LBL-PUB--3093

DE91 016243

\title{
DRAFT
}

\section{Guidelines for Waste Accumulation Areas (WAAs)}

\author{
Revision 0 \\ July 1991 \\ Environment, Health and Safety Division \\ Lawrence Berkeley Laboratory \\ University of California \\ Berkeley, CA 94720
}

Prepared for the U.S. Department of Energy under Contract No. DE-AC03-76SF00098.

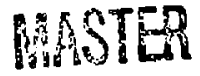




\section{Contents}

1. Introduction 1

1.1 Purpose 1

1.2 Background 1

2. Governing Documents and References 2

2.1 Governing Documents 2

2.2 References 2

3. Definitions 2

4. Responsibilities 4

4.1 Waste-Generating Organization 4

4.2 Waste Generator 4

4.3 Organizational Manager for WAA (and alternate) 5

4.4 HWHF Manager (EH\&S Division) 5

4.5 Environmental Specialist (EH\&S Division) . 5

4.6 Senior HWHF Technician (EH\&S Division) 5

5. Guidelines and Rules Specific to WAAs 6

5.1 Responsibilities for Constructing a WAA 6

5.2 Constructing a WAA 6

5.3 Storing Waste in a WAA $\quad 8$

5.4 Operating and Maintaining a WAA $\quad 15$

5.5 Responding to Spills in a.WAA 20

Appendix A. Official List of Waste Accumulation Areas (WAAs) A-1

Appendix B. Hazardous Waste Disposal Requisition B-1

Appendix C. Who to Call for Further Information C-1

Appendix D. Forms $\quad$ D-1

\section{List of Figures}

Figure 1. LBL Hazardous Waste Label 11

Figure 2. Record of Waste Accumulation Form 14

Figure 3. WAA Daily Inspection Checklist 16

Figure 4. WAA Weekly Inspection Checklist (front side) 17

WAA Weekly Inspection Checklist (back side) 18 


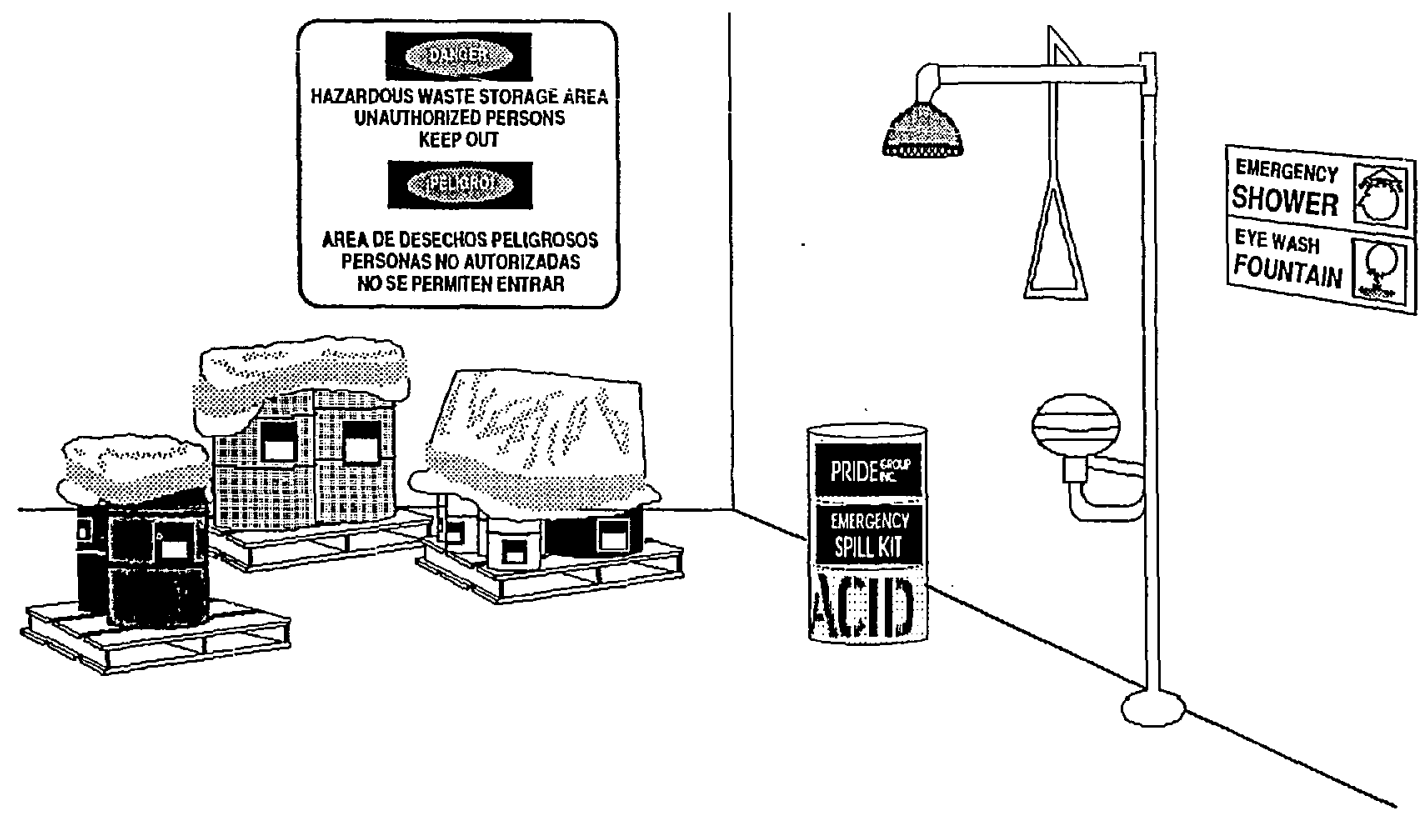

A Waste Accumulation Area 


\title{
Guidelines for Waste Accumulation Areas (WAAs) at LBL
}

\author{
Section 1: Introduction
}

\subsection{Purpose}

The purpose of this document is to set conditions for establishing and maintaining areas for the accumulation of hazardous waste at LBL. Areas designed for accumulation of these wastes in quantities greater than $100 \mathrm{~kg}$ (220 lb) per month of solid waste or 55 gallons per month of liquid waste are called Waste Accumulation Areas (WAAs). Areas designed for accumulation of wastes in smaller amounts are called Satellite Accumulation Areas (SAAs). This document provides guidelines for

- employee and organizational responsibilities for WAAs,

- constructing a WAA,

- storing waste in a WAA,

- operating and maintaining a WAA, and

- responding to spills in a WAA.

\subsection{Background}

Hazardous waste, by definition, can cause serious injury to human health and the environment. Everyone connected with a WAA or SAA must exercise great care to ensure that hazardous wastes are handled safely and correctly at all times.

A casual attitude toward environmental pollution is no longer socially or legally acceptable. Environmental regulators have been using criminal prosecutions against polluters, and the courts are subjecting convicted polluters to heavy fines and even prison terms. Thus, it is vitally important that everyone concerned with hazardous waste understand his/her responsibilities with regard to that waste.

Because of their potential danger to humans and to the environment, WAAs and SAAs must provide storage areas that are secure and that will safely contain any wastes that are spilled or otherwise accidentally released. 


\section{Section 2: Governing Documents and References}

\subsection{Governing Documents}

1. Title 22, California Code of Regulations, Chapter 30, Articles 9 and 11.

2. Environmental Protection Agency, Title 40, Code of Federal Regulations, Parts 260-265.

3. LBL Master Emergency Plan, Pub-237 revised.

\subsection{References}

1. Guidelines for Generators of Hazardous Waste at LBL, PUB-3092

2. Occurrence Reporting, LBID-1694.

3. Aldrich Catalog of Fine Chemicals

4. NIOSH Registry of Toxic Effects of Chemical Substances

5. The Merck Index: An Encyclopedia of Chemicals, Drugs, and Biologicals

\section{Section 3: Definitions}

Waste Accumulation Area (WAA): An officially designated and secured area where large quantities (greater than $100 \mathrm{~kg}[220 \mathrm{lb}$ ] per month of dry hazardous wastes, more than $1 \mathrm{~kg}[2.2 \mathrm{lb}]$ of dry extremely hazardous wastes, or more than 55 gallons of liquid hazardous waste) are collected and stored until they can be picked up for disposal. Waste must be stored in WAAs at LBL for no more than 60 days.

Satellite Accumulation Area (SAA): An area in an individual laboratory, shop, or other facility officially set aside for the accumulation of waste not to exceed 100 $\mathrm{kg} /$ month $(220 \mathrm{lb} /$ month $)$ of dry hazardous waste, one $\mathrm{kg} /$ month $(2.2 \mathrm{lb} /$ month $)$ of dry extremely hazardotis waste, or 55 gallons of liquid hazardous waste.

Hazardous Wastes: Hazardous wastes are

- wastes listed in the California Code of Regulations (22 CCR 66680) and the Code of Federal Regulations (40 CFR Part 26I)

- wastes that exhibit onz or more of the criteria for identification of

"hazardous waste" (22 CCR 66693-66723). These criteria are

- toxicity

- persistent and bioaccumulative effect

- ignitibility

- reactivity

- corrosivity 
- $\quad$ radioactive mixed wastes (materials that contain both hazardous chemical and radioactive wastes)

- wastewater that exceeds sanitary-sewer discharge limits.

Extremely hazardous substance: any of 406 chemicals identified by EPA on the basis of toxicity and listed under SARA Title III.

Ignitable wastes: liquids with a flash point of less than $140^{\circ} \mathrm{F}$, solids that ignite spontanenusly through absorption of moisture or through friction and burn vigorously, flammable gases, and oxidizers.

Storage Time Limit (WAAs only): According to California and Federal codes, the storage time limit for accumulation of waste in a WAA is 90 days, but this time period includes the time needed for transfer of waste to the HWHF and eventual shipment off site. Therefore, the LBL HWHF procedures place a time limit of 60 days at the WAA. This time limit must be adhered to.

WAA Receival or Accumulation Start Date (WAAs only): The date the first drop of waste enters a container. Each container in a WAA may have a different WAA receival or accumulation start date.

Workplace Start Date, Workplace End Date (WAAs only): These dates are for use in SAAs and do not apply to WAAs.

Waste Container: For the purposes of WAAs, a waste container is anything that collects waste in the quantities covered. Waste containers include, in addition to drums and cans, sludge collection traps and underground storage tanks.

Containers in WAAs must be DOT-approved.

Secondary Containment: A container designed to hold one or more waste containers for spill containment of liquid waste. Each secondary containment structure must be able to contain $10 \%$ of the total volume of all containers or the volume of the largest container, whichever is greatest.

Waste Generator: A waste generator is the individual or operation responsible for actually generating the hazardous waste within an organization. LBL as a whole is viewed as a waste generator by environmental regulatory agencies. Within LBL, each researcher, laboratory, shop, and facility, as a potential point of origin for hazardous waste, is a waste generator.

Waste-Generating Organization: the program, facility, or group that generates the waste. 
Waste Stream: Waste generated from an industrial process or application, laboratory experiment, or routine laboratory procedure, with roughly constant and unchanging hazardous and/or radioactivity characteristics.

Cradle-to-Grave Tracking: The system whereby carefully detailed records are maintained documenting the generation, storage, treatment, and disposal of all hazardous waste generated at a facility. These records essentially cover hazardous waste from the point of origin (generation) to its final offsite destination and disposal.

Controlled Area (for radiation protection): an area where radioactive materials or elevated radiation fields may be present.

Segregate in this document means "do not mix" chemically unrelated or incorrpatible materials in the same container; each container in a WAA must contain waste of only one hazard category.

Separate means "set apart physically" in this document.

\section{Section 4: Responsibilities}

\subsection{Waste-Generating Organization}

- assures that the waste is properly segregated, identified, packaged, and stored while in the area of generation (including the WAA)

- transports waste from the area of generation to the WAA

- ensures that all generators in their area receive proper training and are familiar with PUB-3092, Guidelines for Generators of Hazardous Waste at $L B L$.

\subsection{Waste Generator}

- identifies hazardous waste produced by an operation or experiment

- places all waste in the WAA

- notifies the HWHF Technician of the amount, type, and concentration of waste taken to the WAA by entering the information on the accumulation sheet or the Hazardous Waste Label

- contacts the Environmental Specialist or HWHF Technician to ensure that the waste preparation procedures being used meet current environmental standards. 


\subsection{Organizational Manager for WAA (and alternate)}

These individuals are designated by management of the waste-generating organization as being responsible for all activities associated with that organization's WAA, including, but not limited to,

- the daily walkthrough

- maintenance of all logs

- maintenance of all required labeling

- training of individual generators on procedures for use of their WAA

\subsection{HWHF Manager (EH\&S Division)}

- provides management and staff of the waste-generating organization with current guidelines for preparing and storing hazardous waste

- provides technical support and training to the waste-generating organization and the HWHF Technicians on proper ways to segregate, identify, pack.age, store, and transport hazardous waste

- advises and assists generators in preparing hazardous Waste for transfer from work area to WAA, accumulation, and storage at WAA

- sends copies of weekly inspections to Organizational Managers of WAAs

- keeps all documents related to WAAs

- reviews all waste-related activities

\subsection{Environtnental Specialist (EH\&S Division)}

- is responsible for interpreting environmental legal requirements for waste generators and for providing guidance on compliance issues

- advises on the establishment of all WAAs and coordinates approval with the HWHF Manager

- conducts QA surveillance, including inspections and reviews of the waste-handling process, for those WAAs found to be repeat violators of these guidelines.

\subsection{Senior HWHF Technician (EH\&S Division)}

- works with the Environmental Specialist and HWHF Manager in support of waste-related activities

- assists organizations in managing hazardous wastes and in operating WAAS

- assists, when called upon, in the packaging, labeling, and sampling of hazardous waste

- verifies that the waste has been removed from the WAA

- conducts the weekly inspections 
Section 5: Guidelines and Rules Specific to WAAs

\subsection{Responsibilities for Constructing a WAA}

\subsubsection{Organizational Manager}

- consults with the Environmental Specialist and HWHF Manager during the planning, design, and construction of the WAA

- reviews with other EH\&S members, as appropriate, the construction plans from the perspectives of the members' technical disciplines

- identifies the waste that will be generated in the WAA and the containers that will be needed. (All potential waste should be identified before construction of a WAA can begin.)

\subsubsection{HWHF Manager (EHES Division)}

- assists the Organizational Manager and the Environmental Specialist by gathering information on the types, amounts, and locations of hazardous waste being generated

- works with the Environmental Specialist to provide information to the Organizational Manager on design and construction regulations

- approves construction design and location to ensure that all equipment requirements and all containment, enclosure, and siting criteria have been met

- reviews the final plans for vehicle accessibility during waste pickup.

\subsubsection{Environmental Specialist (EH\&S Division)}

- works with the HWHF Manager to provide information to the Organizational Manager on design and construction regulations

- reviews and interprets applicable environmental regulations

- surveys, with the Organizational Manager, the types and amounts of waste being generated

- advises construction design and location to ensure that all equipment requirements and all containment, enclosure, and siting criteria have been met

- coordinates WAA approval with HWHF Manager.

\subsection{Constructing a WAA}

A WAA should be constructed in the area of any organization that routinely generates significant amounts of hazardous waste. The actual need for a WAA is 
best determined by consultation between the management of the wastegenerating organization, the HWHF Manager, and the Environmental Specialist. A WAA cannot be established without prior EH\&S approval.

Sometimes only a temporary WAA is needed, such as in construction areas or in areas where waste generation is irregular or infrequent. However, a temporary WAA must still satisfy the minimum legal requirements for a hazardous-waste storage area. These minimum requirements, which are specific to the particular types of waste being generated, will be determined by the Environmental Specialist.

Once the need has been established for a WAA, whether temporary or permanent, the waste-generating organization is responsible for constructing the WAA.

\subsubsection{Construction Criteria}

During the planning and design stages for a WAA, the responsible organization must work with the HWHF staff and the Environmental Specialist to ensure that appropriate safety and environmental criteria are incorporated into the final design. For details of construction requirements, see the Environmental Specialist. The physical requirements for WAAs are summarized below.

- secondary containment

- shelter from the elements

- limited access

- appropriate signs

- conditions for separation of incompatibles

- at least $\mathbf{5 0}$ feet from the nearest drainage system (sanitary sewer, storm drains)

- sufficient access to allow pickup of waste .

- washable surface (concrete or asphalt)

\subsubsection{Safety Equipment}

The following safety equipment must be maintained at all WAAs:

- fire extinguisher

- emergency spill kit

- emergency eyewash

- telephone

- protective equipment (e.g., gloves, safety glasses)

- hazard warning signs (e.g., Flammables, Hazardous Waste Area)

- posted procedures for collection (identification, segregation, dating) 
- posted contingency plan for dealing with spills and other accidental releases of hazardous wastes

- posted names and telephone numbers (day and night) of responsible individuals (WAA supervisor)

\subsection{Storing Waste in a WAA}

Hazardous waste that has been properly segregated, identified, and packaged may be stored in a WAA at LBL for up to 60 days. Within that time period, the viaste will be removed by HWHF personnel for disposal.

The main elements of waste storage in a WAA include

- segregation of wastes

- separation of wastes

- containers for separation and segregation of wastes

- chemical identification and characterization

- labeling

- packaging in a WAA

- storage time limits

- transfer of waste to a WAA

- transport of waste to the HWHF

- spill prevention

These subjects are discussed below.

\subsubsection{Segregation of Wastes}

The generator must segregate hazardous wastes into individual containers according to the type of material. Segregation is important for three reasons: safety, disposability, and recyclability.

Safety. When chemicals are mixed without regard to their compatibility, safety hazards can result: for example, the resulting mixture could explode or produce toxic gases. A safe rule tor mixing chemicals is When in doubt, DON'T MLX. Call the EH\&S Environmental Specialist, $x$ 4644, for help.

Disposal requirements. Certain chemicals can be disposed relatively cheaply. But that same chemical, if contaminated with certain other chemicals, becomes very expensive or difficui: to dispose. The classic exampie is any hazardous chemical contaminated with radioactive wastes, no matter how low the radioactivity level. Radioactive mixed wastes, as these types of wastes are called, are not currently disposable anywhere. 
Recyclability. As with disposability, certain chemicals can be recycled at great savings to LBL, but small amounts of other chemicals mixed into these chemicals render the original chemical unrecyclable. For example, waste oil is recyclable, but a few tablespoons of halogenated solvent in a 55-gallon barrel of waste oil will render that barrel of oil unrecyclable.

\subsubsection{Separation of Wastes}

Separate your cheinicals into the classes designated on the Hazardous Waste Disposal Requisition (Appendix B). Each secordary containment must contain only compatible chernicals. Separation of chemicals is important to avoid crosscontamination of incompatible chemicals in the event of spills.

Note that WAAs are for nonradioactive wastes only. Radioactive wastes must be kept in areas separate from WAAs.

\subsubsection{Containers for Separation and Segregation of Wastes}

Obtain and set up your waste containers based on the following rules:

\begin{tabular}{|l|l|l|}
\hline \multicolumn{1}{|c|}{ Waste Type } & Approved Container & \multicolumn{1}{c|}{ How to Obtain } \\
\hline Liquid wastes (large quantities) & 55 -gal DOE 17E drum & Contact EH\&S \\
Solid wastes (large quantities) & 55-gal DOE 17H drum & Contact EH\&S \\
$\begin{array}{l}\text { Small individual waste } \\
\text { containers }\end{array}$ & Plastic tote box & Stores item 8115-66258 \\
Asbestos & $\begin{array}{l}\text { Double plastic bags } \\
\text { labeled ASBESTOS } \\
\text { Mercury }\end{array}$ & $\begin{array}{l}\text { Stores item 8105 series } \\
\text { (depending on size) }\end{array}$ \\
PCB-containing wastes & $\begin{array}{l}\text { Containers } \\
\text { Call EH\&S for details }\end{array}$ & \\
\hline
\end{tabular}




\subsubsection{Chemical Identification and Characterization}

The waste-generating organization is responsible for identifying and characterizing wastes. When necessary, the HWHF Technician will assist the program by taking samples and arranging for appropriate analyses of waste. See PUB-3092, Guidelines for Generators of Hazardous Waste at $L B L$, for details.

Waste can be identified in three ways:

- chemical name and structural formula, with volume and concentrations

- manufacturer and specific product

- complete generic description of the material

The generator is also responsible for requesting chemical analyses on all unknown materials to determine their hazardous components before these materials are picked up by the HWHF. A copy of the laboratory report must accompany the HWHI: Hazardous Waste Disposal Requisition. For assistance in having unknown materials identified, contact the Environmental Specialist. Further details on chemical identification and analysis of wastes is provided in PUB-3092, Guidelines for Generators of Hazardous Waste at LBL.

\subsubsection{Labeling}

Once determined, the identity of the waste in each container must be recorded on the Hazardous Waste label (Figure 1) attached to the container. In accordance with current environmental regulations, the label must provide the following information (the numbers are correlated with the numbers in Figure 1):

- Generator (1): Enter the name and building of the person generating the waste.

- Phone number (5): Enter the generator's LBL telephone number.

- Contents (2): Give the chemical names, material names, or waste stream of the waste, and describe the composition of the waste.

Samples of chemical or material nanes include

- Petroleum-based motor oil, 1110 ("1010 motor oil" would not be adequate)

Samples of waste streams include

- Aqueous wash water, $10 \%$ acetone

- Machine ard grinding coolant (MasterChem Trimsol) with zinc particles

- WAA Receival or Accumulation Start Date (4): Enter the date on which waste is first placed in the container. 


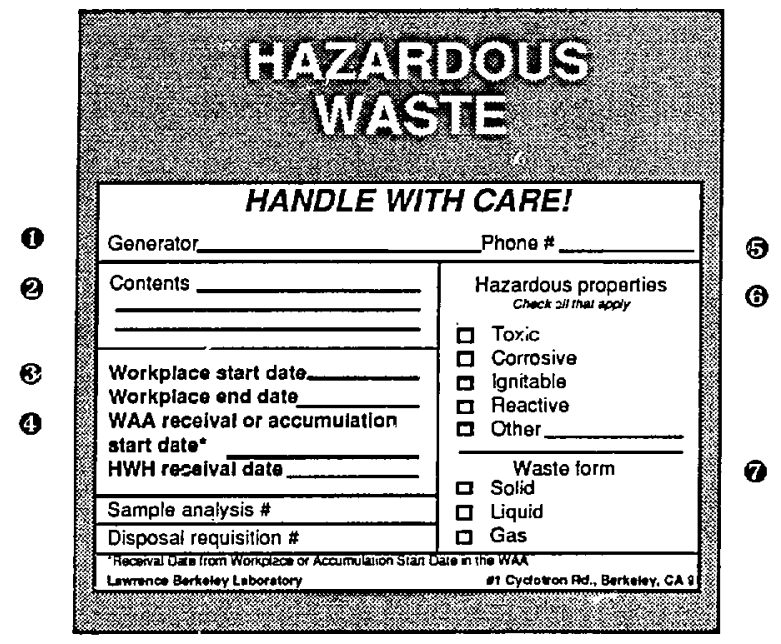

(1) Generator: Enter name and building of person generating the waste.

(2) Contents: Give chemical name, material name, or waste stream description. Lescribe composition of waste.

3 Workplace start date, workplace end date: Leave blank for WAAs.

4 WAA receival or accumulation start date: Enter date waste is first placed in container.

(9) Phone Number: Enter generator's LBL phone number.

(6) Hazardous properties: Check appropriate boxes.

( Waste form: Check appropriate box.

Figure 1. LBL Hazardous Waste label 
- Workplace Start Date, Workplace End Date (3): Enter "NA" for "not applicable." These dates are for use in SAAs.

- Hazardous Properties (6): Check appropriate boxes.

- Waste Form (7): Check the appropriate box (solid, liquid, or gas).

Add other labels (e.g., carcinogenic, PCBs) as appropriate. If you have any questions regarding appropriate labeling, call the HWHF Technician, x 7625.

Please note that the dating requirements on the Hazardous Waste label differ for WAAs and SAAs. The following short table summarizes the dating requirements on the Hazardous Waste label for WAAs.

\begin{tabular}{|c|c|c|}
\hline Term & WAA Definition & WAA Usage \\
\hline $\begin{array}{l}\text { WAA receival or } \\
\text { accumulation } \\
\text { start date }\end{array}$ & $\begin{array}{l}\text { Date when waste is first } \\
\text { added to container }\end{array}$ & $\begin{array}{c}\text { Fill in current date when } \\
\text { waste is first added to } \\
\text { container }\end{array}$ \\
\hline $\begin{array}{l}\text { Workplace } \\
\text { start date }\end{array}$ & Does not apply to WAAs & $\begin{array}{c}\text { Enter "NA" (for "not } \\
\text { applicable") }\end{array}$ \\
\hline $\begin{array}{l}\text { Workplace } \\
\text { end date }\end{array}$ & Does not apply to WAAs & $\begin{array}{l}\text { Enter "NA" (for "not } \\
\text { applicable") }\end{array}$ \\
\hline
\end{tabular}

\subsubsection{Packuging in a WAA}

The generator is responsible for packaging the waste so that it may be safely transported and stored pending disposal. HWHF personnel will remove waste from the WAA only if it is packaged in tightly closed, properly labeled, approved containers that show no signs of damage, deterioration, rusting, or leaking.

\subsubsection{Storage Time Limits}

Hazardous waste may be accumulated in a WAA at LBL for a maximum of 60 days and stored at LBL for no more than 90 days, unless special permits are obtained from environmental regulatory agencies. The beginning of the 90-day storage period is called the WAA receival or accumulation start date, which is the date when waste is first placed in the container. This date is recorded on the Hazardous Waste label attached to the container. 


\subsubsection{Transfer of Waste to a WAA}

Transfer of hazardous waste from the point of generation to a WAA must be by a method agreed on between the generator and the HWHF staff. In most cases, the generator may take waste to the WAA and add it to the appropi iate labeled containers, which will remain at the WAA until filled or until the 60-day limit is rezched. When placing waste in the container, the generator must enter on the Fecord of Waste Accumulation form (see Figure 2) the date, generator's initials, and type and amount of waste being added at that time.

\subsubsection{Transport of Waste to the HWHF}

Waste is transported from the WAA to the HWHF by HWHF staff and contract vendors. Before HWHF staff or contract vendors will pick up waste containers from a WAA, the HWHF Technician must inspect the waste package and sign the Hazardous Waste Disposal Requisition (Appendix B), verifying that the package is safe to transport. HWHF will review the requisition and, if it is approved, schedule a pickup date. No waste will be accepted without complete labels and an accurately completed Requisition.

\subsubsection{Spill Prevention}

A properly designed WAA must have secondary containment to prevent accidental release of hazardous substances to the environment. Secondary containment can be either a concrete berm surrounding the perimeter of the WAA or a specially designed fiberglass hazardous-waste containment tray, equipped to hold up to 60 gallons of liquid, placed under each pallet of hazardous waste materials. The containment tray is available for purchase through an outside vendor; HWHF staff can advise the generator on spill-prevention equipment.

Spill prevention methods include the following, which are also regulatory requirements:

- Keep all containers closed except when adding waste.

- Generators must assure that loose funnels are removed from the openings of liquid waste drums and that caps or lids are secured after each addition of waste. If screw-in funnels are used, the lid must be closed except when adding waste.

- The written contingency plan and emergency kit must be readily accessible.

- Emergency equipment (for example, safety showrer and eyewash) must be accessible and in good working order. 


\section{I3. LAWRENCE BERKFLEY LABORATORY RECORD OF WASTE ACCUMULATION}

\begin{tabular}{|c|c|c|c|}
\hline $\begin{array}{l}\text { DATE } \\
A D D E D\end{array}$ & DESCRIPTIONOFWHATWASADDED & AMOUNT & INTTLLS \\
\hline $6 / 7 / 91$ & Ethyl Acotato & $500 \mathrm{ML}$ & SBS \\
\hline $6 / 7$ & Mothanol & $.5 \mathrm{~L}$ & wo \\
\hline $6 / 8$ & Hoxane & $1.0 \mathrm{~L}$ & RAJ \\
\hline $6 / 10$ & Acetone & $1.0 \mathrm{~L}$ & wC \\
\hline $6 / 15$ & Acetone & $.2 \mathrm{~L}$ & SBs \\
\hline $6 / 15$ & Ethyl Acotate & $.1 \mathrm{~L}$ & KMN \\
\hline-646 & Asotono- & $-100+1 \mathrm{t}$ & $\mathrm{RAl}$ \\
\hline $6 / 20$ & Mythanol & $.2 \mathrm{~L}$ & $w c$ \\
\hline $6 / 21$ & Acotone & $2.0 \mathrm{~L}$ & we \\
\hline $6 / 23$ & Ethyl Acetaite & $2.0 \mathrm{~L}$ & we \\
\hline $6 / 23$ & Hexane & $1.2 \mathrm{~L}$ & KMMN \\
\hline $7 / 1$ & Acsotone & $.5 \mathrm{~L}$ & SBS \\
\hline $7 / 1$ & Acetone & $1000 \mathrm{ML}$ & we \\
\hline $7 / 2$ & Ethyl Acetate & $1.0 \mathrm{~L}$ & SBS \\
\hline $7 / 2$ & Acotone & $3.0 \mathrm{~L}$ & RAd \\
\hline $7 / 3$ & Acontre Methand & $0.2 \mathrm{~L}$ & KMN \\
\hline & 715 & & \\
\hline & & & \\
\hline & & & \\
\hline & & & \\
\hline & & & \\
\hline & & & \\
\hline & & & \\
\hline
\end{tabular}

Figure 2. Record of Waste Aciumuiation form. See Appendix D for full-sized form. 


\subsection{Operating and Maintaining a WAA}

\subsubsection{General}

The waste-generating organization is responsible for operating and maintaining the WAA in such a way that hazardous waste is properly handled and is not released to the environment.

The waste-generating organization must designate an Organizational Manager to operate and maintain the WAA. This designated individual, along with appropriate technicians, as noted below, will make formal inspections of the WAAs, prepare containers for pickup by the HWHF, and maintain a current contingency plan.

\subsubsection{Inspections}

Two types of inspections are required: a daily walkthrough, and a weekly survey. The daily walkthrough, performed by the Organizational Manager or his/her designee, should be able to identify potential problems within 24 hours of occurrence. Problems identified during the daily walkthrough must be logged on the Daily Inspection Checklist and corrected immediately, if possible. It is a regulatory requirement that deficiencies be corrected in a timely manner and that records be kept documenting all repairs and other corrections made. Figure 3 shows the Daily Inspection Checklist. Daily Inspection Checklists must be kept for at least three years in binders labeled "WAA Daily Inspection Checklists." These binders must be readily available at all times for inspection by EH\&S staff and other regulatory personnel.

The weekly inspection must be performed by one of the HWHF Technicians. The inspections are to be logged on the Hazardous Waste Accumulation Area Weekly Inspection Checklist, shown in Figure 4. These records must be kept by EH\&S for at least three years and must be available for inspection by regulatory agencies.

Weekly inspections of WAAs are required by both Federal and state regulations, which are designed to ensure environmental protection and safe operation. The following items must be checked:

- Use of appropriate containers and proper packaging of waste in containers. Lids on containers must be securely closed. Containers must be checked to ensure that they are compatible with the waste and that the waste has been packaged correctly.

- Separation of incompatible wastes. There should be adequate separation in the WAA between any incompatible wastes and between ignitible wastes and sources of ignition. Aisle space between pallets 


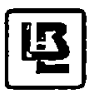

\section{LAWRENCE BERKELEY LABORATORY \\ WASTE ACCUMULATION AREA DAILY* INSPECTION CHECKLIST}

\begin{tabular}{|c|c|c|c|c|c|c|}
\hline \multicolumn{2}{|c|}{ 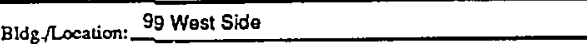 } & \multirow{2}{*}{$\begin{array}{l}\text { Time AM. } \\
\text { WEEKOF }\end{array}$} & \multicolumn{2}{|c|}{$7: 15$} & & 3:05 \\
\hline \multicolumn{2}{|c|}{ Inspector: K. Nosbitt } & & $7 / 1$ & & & \\
\hline & MORNINC CHECKLIST & $M$ & $T$ & W & $\mathrm{Th}$ & $\mathbf{F}$ \\
\hline l. & Check all dirut kops for shanding waver & WN & $K N$ & $K N$ & KN & $\mathrm{KN}$ \\
\hline 2. & Check all palless for stunding water & $\overline{K N}$ & $\mathrm{KN}$ & $\mathrm{KN}$ & KN & KN \\
\hline 3. & Check all drums for closed/sealed lids & KN & KN & & $\overline{K N}$ & $\overline{\mathrm{KN}}$ \\
\hline 4. & Check all thums for correcutreadable labeis & KN & $\mathrm{KN}$ & $\mathrm{KN}$ & KN & KN \\
\hline 5. & Are aisles ind doorways free of obstructions? & WN & KN & KN & $\mathbf{K N}$ & KN \\
\hline 6. & Are berm areas and containment systzms free of leaks and spills? & 10N & KN & $\mathrm{KM}$ & $\overline{\mathrm{KN}}$ & KN \\
\hline 7. & Are all start dares in compliance with the 60-day limitalion? & $\mathrm{KN}$ & $\mathbf{K N}$ & & $\mathbf{K N}$ & $\mathrm{KN}$ \\
\hline
\end{tabular}

\section{EVENING CHECXIST}

\begin{tabular}{|c|c|c|c|c|c|}
\hline Check that all drum covers are on tight & $\mathrm{KN}$ & $\mathrm{KN}$ & KN & KN & $\mathrm{KN}$ \\
\hline Check that all drums are labeled & KN & KN & KM & $\mathrm{KN}$ & KN \\
\hline Check that all areas are seetred and gates are locked & $\mathrm{KN}$ & KN & $\mathrm{KN}$ & $\mathrm{kN}$ & $\overline{K N}$ \\
\hline & & & & & \\
\hline & & & & & \\
\hline
\end{tabular}

\begin{tabular}{|l|l|l|}
\hline $\begin{array}{c}\text { Date } \\
\text { Conrected }\end{array}$ & $\begin{array}{c}\text { Cortected } \\
\text { By }\end{array}$ & \multicolumn{1}{c|}{ COMMENTSCORRECTIVE ACTION } \\
\hline $7 / 3 / 99$ & RM & 3. Flammable solid onty partially covered. Now label put on, container closed. \\
\hline $7 / 8 / 91$ & $\infty$ & 7. Caustic liquid in caustic shed over 90 days. Moved to 1 year storage. \\
\hline & & \\
\hline & & \\
\hline & & \\
\hline & & \\
\hline & & \\
\hline
\end{tabular}

(HWHF SRAI)

*Daily refers to day of operation

Figure 3. Waste Accumulation Area Daily Inspection Checklist. See Appendix D for full-sized form. 
Bldg Jocution:_e9 Machine Shop

Dace: $7 / 1 / 91$ Time: 9:00 am

Inspector: Rita Cummings/Regaie Marinez

(If NO is checked, docwnent the details in the comments section on reverse side.)

1. Area posted with appropriate hazard and cautionary signs?

2. Area free of spills?

3. All liquids stored in proper secondary contrinnent?

4. Secondary containment besin free of liquid and debris?

5. Containers compatible with waste being stored?

6. Containers properly sealed (lids $\mathrm{cn}$, rings in placs, caps on furnels, etc.)?

7. Pallets in guod condition?

8. Emergency and safery equipment (spill kits, eyewash, elc.) eccessible and in operaing condition?

9. Current contingency plen visibly posted?

10 All contuiners properly labeled?

11 Labels easily visible for inspection?

12 Accumulation start date present on label?

13 All accumulation star dates within the 60-day limit?

14 Informacion on labels legible, not faded, and all required informacion is present?

15 Adequate aisle space (minimum 22 inches)?

16 Containers free of leaks, dents or ceterioration including struewral defects and rusting?

17 Adequate separation of incompatible materials?

\begin{tabular}{|c|c|c|}
\hline $\begin{array}{c}\text { Date } \\
\text { Corrected }\end{array}$ & $\begin{array}{c}\text { Cortected } \\
\text { By }\end{array}$ & COMMENTS/CORRECTTVE ACTION \\
\hline $7 / 12 / 91$ & $\infty$ & 1. Hazardous wasto warning sign missing \\
\hline $7 / 1 / 91$ & RAM & 2. Water on top of drum \\
\hline $7 / 291$ & PAM & 8. Eyewash hasnt been flushed in 4 weeks \\
\hline \multirow[t]{2}{*}{$7 / 1 / 91$} & RAM & 11. Conosive drum labals facing in \\
\hline & & Soe reverse side \\
\hline
\end{tabular}

(HWHF 7/1291 CCRCISB)

Figure 4. Hazardous Waste Accumulation Area Weekly Inspection Checklist (front side) 


\section{HAZARDOUS WASTE ACCUMULATION ARE WEEKLY INSPECTION CHECKLIST CONTINUED.}

\begin{tabular}{|c|c|c|}
\hline $\begin{array}{c}\text { Dare } \\
\text { Corrected } \\
\end{array}$ & $\begin{array}{c}\text { Compeced } \\
\text { By }\end{array}$ & COMMENTS/CORRECTIVE ACTION \\
\hline $7 / 10 / 91$ & RMCC & 13. Waste oil accumulation start date $4 / 10 / 91$ \\
\hline $7 / 2 / 91$ & RAM & 14. Waste dry absorbent spill cleanup has faded label \\
\hline & & \\
\hline & & \\
\hline & & \\
\hline & & \\
\hline & & \\
\hline & & \\
\hline & & \\
\hline & & \\
\hline & & \\
\hline & & \\
\hline & & \\
\hline & & \\
\hline & & \\
\hline & & \\
\hline & & \\
\hline & & \\
\hline & & \\
\hline & & \\
\hline & & \\
\hline & & \\
\hline & & \\
\hline & & \\
\hline
\end{tabular}

(HWHF 7/12/91 CCRC/SB)

Figure 4. Hazardous Waste Accumulation Area Weekly Inspection Checklist (back side) 
should be adequate to conduct routine maintenance and inspection activities and for any necessary emergency response.

- All safety equipment must be in its proper location, easily accessible, and in good operating condition.

- A Hazardous Wasie label, completely filled out, must be affixed to each container.

- Drums and containers must be off the ground, on pallets, racks, or counters.

- Containers must show no signs of deterioration, rusting, dents, or leaking. All spills must be identified and acted on immediately.

- The date, time, building, and name of the person conducting the inspection must be written on the inspection sheet.

\subsubsection{Record-keeping}

The Organizational Manager must keep the following records relating to the WAA:

- WAA Daily Inspection Checklists (described above)

- Copies of all Hazardous Waste Disposal Requisitions

- Copies of all Record of Waste Accumulation forms

- Waste profiles, with profile numbers, for their facility.

All records must be kept for at least three years. They should be lept in the Organizational Manager's office, and they should be organized well enough that regulatory personnel would have no trouble reviewing the records for the WAA for at least three years.

\subsubsection{Preparing Containers for Pickup}

The Organizational Manager must arrange for waste to be picked up from the WAA within 60 days of the Accumulation Start Date by faxing the completed Hazardous Waste Disposal Requisition and other supporting documentation as necessary (Waste Profile Worksheet, Laboratory Waste Analysis Request Form, Record of Waste Accumulation Form) to EH\&S, $\times 4838$. In order to allow time to transfer the waste to the HWHF, it is recommended that the Requisition be submitted two weeks ahead of the deadline. When inspecting and approving containers for pickup by the HWHF, the HWHF Technician must ensure that the containers meet appropriate safety criteria. In case of error, the generator will repackage the waste under the direction of the HWHF Technician. 


\subsubsection{Maintaining a Current WAA Contingency Plan}

The Organizational Manager, working with the Environmental Specialist, must develop a contingency plan for dealing with spills or other accidental releases of hazardous waste in the WAA. This contingency plan must be based on the types of hazardous wastes accumulated in the WAA and must be updated as necessary to reflect any changes in the waste streams. The contingency plan, and all updates, must be approved by the Environmental Specialist. Originals of WAA contingency plans are filed with the HWHF Manager.

The contingency plan must include the following:

- a list of emergency equipment (spill kit inventory, eyewash and safety show $€$, fire extinguisher)

- a map showing the location of each item of emergency equipment

- a list of wastes specific to the WAA, listing generic and brand name, hazard class, average and maximum quantities, and spill response category associated with each type of waste,

- a description of the proper response procedure to a spill of each type and quantity of waste

- a map of evacuation routes out of the building (away from the WAA)

- a map of evacuation routes from LBL to the nearest hospital.

The following must be posted prominently within the WAA, in clear waterproof plastic protective sleeves, in a manner so that they are easily visible from outside the WAA:

- the contingency plan itself in its entirety

- a list of emergency equipment

- a map showing the location of each item of emergency equipment

- a map of evacuation routes out of the building (away from the WAA)

- a map of evacuation routes from LBL to the nearest hospital.

The contingency plan must not conflict with any elements of LBL's Master Emergency Plan (Pub-237 Rev.) or the Building Emergency Ilan for the building or area in which the WAA is located.

\subsection{Responding to Spills in a WAA}

If a spill does occur, the primary aim of the response must be to picict human health and the environment. Spills are categorized as either small spills or large spills. 


\subsubsection{Small Spills}

A small spill is defined as one in which

- the nature and hazards of the spilled material are known,

- the material does not have a perceived threat to human health or the environment, and

- the spill is small enough to be cleaned up quickly and safely by one or two people within one hour.

If a small spill does occur, the responsible program individual should immediately determine the source, type, and amount of leaking material and then follow the procedure outlined in the contingency plan for cleaning up a spill of that type of waste. If there is any uncertainty about safely managing the spill, the responsible individual should call the following number immediately:

- ICS phones: 7911 (LBL Fire Department)

- Offsite locations: 9-911 (City of Berkeley Emergency Services)

The Senior HWHF Technician and the Environmental Specialist should be informed of all spills on the day they occur. The Environmental Specialist will investigate the incident, confirm the type and amount of material spilled, and determine if the spill is a reportable incident, as defined by environmental regulatory agencies. DOE reporting rules for all spills are detailed in LBL's Occurrence Reporting document, LBID-1694.

Should the spill be reportable, EH\&S personnel will assist the responsible organization in handling all notification and reporting requirements of the appropriate environmental agencies. The Environmental Specialist will

- verify cleanup,

- conduct follow-up sampling, if necessary, and,

- in consultation with the generator, recommend acticns to be taken by the waste-generating organization to correct the problem and avoid similar incidents in the future.

The HWHF Technician should record the spill incident in his/her logbook. 


\subsubsection{Large Spills}

A large spill is defined as one in which

- the nature of the material and the potential hazards are not known or are in question,

- the spill is perceived as an immediate actual or potential threat to public health or the environment, and

- the spilled material requires more than one or two people to clean up the spill safely within one hour.

In the event of a large spill or fire, the Fire Department or City of Berkeley Emergency Services should be called immediately at the emergency number:

- ICS phones: 7911 (LBL Fire Department)

- Offsite phones: 9-911 (City of Berkeley Emergency Services)

Provide the Fire Department or Emergency Services with the following information:

- location of spill

- $\quad$ source of spill

- type of material

- amount of spilled material

- any exposure to personnel.

For Hill spills, the Emergency Dispatcher at the LBL Fire Department will notify the HWHF, whose staff will respond to the spill and assist the Fire Department in stabilization of the incident. EH\&S emergency response staff, taking direction from the Incident Commander (LBL Fire Department), will assess the threat to the environment and advise on cleanup procedures. EH\&S will also respond and coordinate appropriate disposal activities. The Division Director of the affected division will be informed of the incident so that he or she can determine the need and level of the occurrence for reporting purposes.

The Environmental Specialist will write an internal Environmental Incident Report for the EH\&S Division Director and the Division Director of the affected organization. 
Approved By:

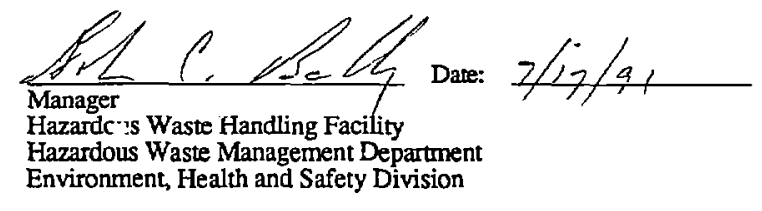

Approved By:

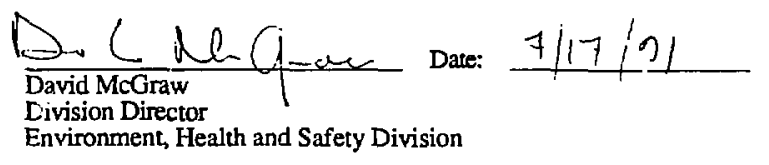

Approved By:

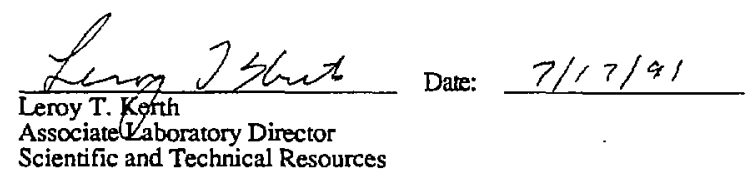




\section{Appendix A. Location of Waste Accumulation Areas (WAAs)}

\begin{tabular}{|c|l|l|l|c|}
\hline Building & \multicolumn{1}{|c|}{ Location } & \multicolumn{1}{|c|}{ Division } & \multicolumn{1}{c|}{ Contact } & Phone \\
\hline 25 & West side of bldg. & Engineering & Al Kanzaki & 5562 \\
\hline 51 & $\begin{array}{l}\text { South side of } \\
\text { bldg. }\end{array}$ & Administration & Mac Morgan & 6011 \\
\hline 58 & Northwest door & AFRD & Bob Berninzoni & 5387 \\
\hline 62 & $\begin{array}{l}\text { North side of } \\
\text { bldg. }\end{array}$ & AFRD & Ralph Hipple & 6372 \\
\hline 76 W & East side of bldg. & MSD, CSD & Peter Ruegg & 5395 \\
\hline 76 Paint & East side of bldg. & Administration & Paul Stonas & 5339 \\
\hline 76 Motor \\
Pool
\end{tabular}


GENERATOR INFORMATION

Operating Account No.

Payroll Account

Has this information

been FAXED beture?

Yes

No

Name (printed)

Department

Project

Phone

Date

Material Location (Bldg., Rm, etc.)

INSTRUCTIONS: Please provide all information requested. List no more than one container per line (use additional lines lo describe container contents, it needed). Use separate packing listfis for each box of containenized material. Your signature is requised and certifies that to the best of your knowledge, the chemical composition provided for each item is correct.

Complete all entries or your request will be renmed for clanification.

1

Chemical Characterization of Wasto (Do nol use abbreviations)

2

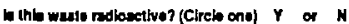

3

In this wete redbectlve? (Clecto one) $Y$ or $\mathrm{M}$

4

L this wede radiasctive? (Circle one) $Y$ or $\mathrm{H}$

5

L this wate redoectlyo? (Clisk one) $Y$ or $A$

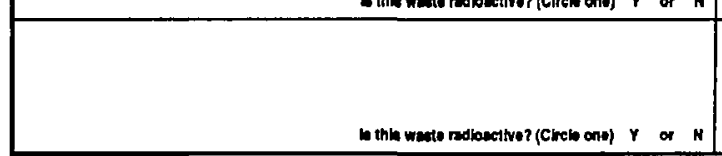

"CODE: 1

2

31

$3 b$

\begin{tabular}{|c|c|c|c|c|}
\hline 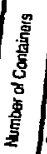 & 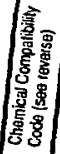 & 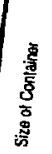 & 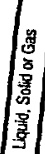 & 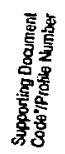 \\
\hline
\end{tabular}

SUPPORTING DOCUMENTATION: Process knomedge

MSDS

Wasto Profite ID Number

Waste Profile Workshegr

Laboratory Anaysis Pepor

Based upon my knowledge of the waste, andyor chemicalyphystal analysts, I centily that the inlormation provided regarding the waste specified on this form is corred. I understand that this information will be made availabb lo regulatory agencies and that there are signiflcant penalies for submiting falso intormation, induding the possbility of flines and imprisonment lor knowing viotatbns.

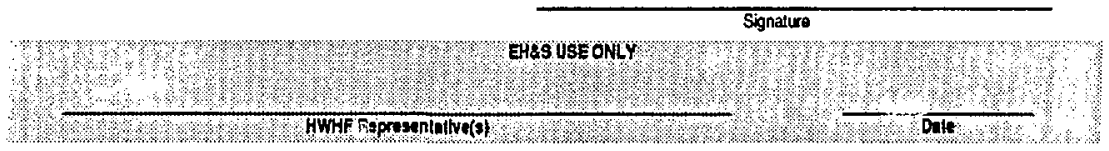




\section{LBL hazARDOUS waSTE DISPOSAL PACKAGING REQUIREMENTS}

The following requirements must be met as a condition for pick-up and disposal of chemicals by Environment, Health and Safety (EHsS). If you have questions or unusual problems, piease call EH8S at extension 5251 for assistance.

i. It is Laboratory policy not to fush any hazarous substances down the LBL sewer system. EH\&S must review and approve the disposal of all hazardous substancas to the sanitary sewer for compliance, as weil as for salely issues. Waching contaminated glassware is an example. Highly pxic, malodorous, or lachrymalory chemicals should not be disposed of down the drain, Laborabory drains are generally interconnected; a substance thal goes down one sink may wetl come up as a vapor in another. There is a very leal hazard of chemicals from two soutcos contacting one another; the sulfide poured into one drain may contact the acid poured into another, with unpleasant consequences for all in the building. Somo simple reactions can even cause explosions (e.g., ammonia plus iodine, silver nitrate plus ethanol, or picric acid plus laad salss).

2. Chemicals must be soparated into compacible groups. A compatibility guids is provided below and a more debiled version is altached for referonce.

3. Leaking conteiners ol any sort will not be accepled.

4. Dy materiats (gloves. wipes, pipettes, eic.) mus! be securely contained in double plastic bags and overpacked in a cardboard box. Packages that are wet of have shatp protruding objects will not be acceptad.

5. Unknown chemicals cannot be accepted by the Hazardous Waste Handling Facility (HWHF). The responsible depertment must make every effor to identity the material designated tor disposal. If all the user's attempts to idenily the waste chemicals have hiled. EHsS will aid in the sampling of said waste and will charge the user's account for andysis. For more intormation call the HWHF Manager at extension 6146.

6. Each breakable container must be propery boxed. Place all boutes in plastic bags. Then place the bags in a sturdy container and use an absorbent cushioning material that is compajble with the chemicals.

7. Each primary container must be labeled with content anount, physical state, and the percenege breakdown when dealing with a mixture.

8. Each conganer must have a complece list ol contente or description written on an olficial LBL Hazardous Waste Disposal Requisition lorm. Blank torms are avalable trom your division office.

9. Containers must be of a reasonable size and weight 50 that one person is able to handle them safely. Conaines that axceed 45 pounds or t8 inches on a side cannos be sately handed by one person and will not be accepled. Aurangements must be made with HWHF for transportacion of large items.

10. Avdid accunulaung iaboretory chemicalst Request toquent chemical pick-up.

11. Do not accumulate any wasles tet over 60 days at a Wasb Accumulation Area (WAA) or over 275 deys at a Satellite Aceumulation Area (SAA).

\section{SUPPORTING DOCUMENTATION REOUIREMENTS}

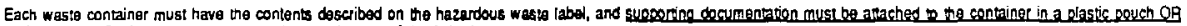
on file ar HWHE. Supporting documentation can ba ong of the following:

(A) Process knowledge of westes whose composition is doctmented by the procedures generaing them; (B) records of accumulation - a log that contains an entry each dime waste is addod to a container: (C) an MSDS for all chemicaleimetenials used in an experiment or process; (D) an MSOS for spent of unused materials; (E) a

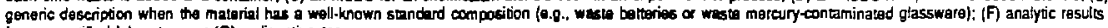

from a certified laboration. of (G) radionetive ung.

Waste Profiling. If the papenwork submitted suppors the deceription of the westo stream adequetely, and the waste strean will not change over imo, HWy will ascign a

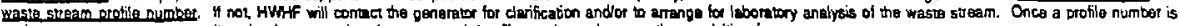
assigned, the generalor enters it under the eupporing document code/profile number column on the recuitition form.

\section{PICKUP AND TAANSPORTATION}

An LBL Hazardous Wasto Dispoes Requisition form must be FAXed to HWHF. Extension 4838 is dedicated to this purpose.

Keep wo copies of the requisition form; attech one copy to the conbingre bo pickod up and put the other in your file or work binder as a generabr record.

CHEMICAL COMPATIBILJTY GUIDE

Separating chemicals into compatible groupe can be a complicatad procedure. There are several indopth guides aveilable. For the purposes of peckaging chemicals for removal Irom the Laborabry. EH\&S provides the tollowing simplified guide on the following page. Additional intermation on proper segregation of chemicals ean be teund in

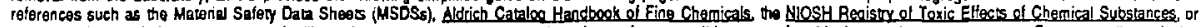
the Marck Index. Laboratory personnel will be able os segrepate mast chemicals inso sale, compatible groups tor shipping at shon-term storago. For potentally explosive chemieals. conect industrial hypiene at extension 5829 br acsistance. Contect HithF tor questions about seperasion and sogrogabion of waste.

CHEMICAL COMPATIBILITY CODES

I. Solvents - Flammable Liquids, Combustible Liquids

il. Flemmatia Solide - Organic, Nabols, Solids that are dengerous when wor Sulfides. Phosehorous Aliotropes, Orgenomotilic Compounds. inomanics

III. Oxidizers - Niwales, Chlorates, Perchlorates, Orites, Oridizing Acids

IV. Corrosives .

Acide (Hinera, Organic, Reactre Conosives);

gases (inorganics, Organics, Hydrazins Solutions)
V. Poisons - Oparics. Masalics Inorganic Cyanides

VI. Patenial Ractives \{Explasive\} - Trinizos, Azidoc, Amides, Monomeric Isocyanates

VIL Other Chamical Westa - Seporate organics from inarganics. Seperate liquids from solids.

VII. Debris - Separeto omenies from inorganics and label peckaging with all contaminanes present 
Identifying and recognizing the hazards of each chemical is critical in order to handle these materials safely.

To meet safety and environmental requirements, the following basic categories must be used for segregating and separating your waste.

1. Solvents

A. Flammable Liquids

1. Aliphatic:

Acetone, Isopropanol, Methyl Ethyl Ketone, Methanol

2. Aromatic:

Toluene, Xylene, Benzene, Propyl Benzene

3. Monohalogenated Solvents:

Chlorobenzene, Ethyl Chloride, Acetyl Chbride

4. Monomers:

Styrene. Ethylene, Vinyl Acetylene, Vinyl Pyridine

5. Reactives:

Isopropyl Ether, Phenyl Manganese Chloride, Hydrazine Anhydrous, Ethyl Ether, Divinyl
Ether

B. Combustible Liquids

1. Glycols:

2. Mineral Spirits

Ethylene Glycol Dibutyl Ether, Ethylene Glycol Monomethyl Ether

c. Halogenated Solvents

Carbon Tetrachloride, 1,1,1-Trichloroethane Ethyl Chloroacetate

II. Flammable Solds

A. Organic Flammable Solids:

B. Flammable Metals:

Cellulose Acatate, Nitrocellulose (At least 20\% wet)

Manganese, Magnosium, Yttrium, Ziroonium

C. Flammable Solids (Dangerous when wet):

D. Flammable Sulfidos:

Sodium, Lithium, Cakcium, Lithium Hydrida

E. Phosphorous Allotropes:

Sodium Sulfide, Potassium Sulfide, Ammonium Sulfide

Phosphorus (Yellow, Red, Whito), Aluminum Phosphide, Phosphorus Sulfide,

F. Organometailic Compounds:

Lithium Butoxide, Lithium Metoxide, Sodium Ethoxy, Sodium Butylate, Potassium

Methylate

G. Inorganic Flammable Solids:

Sodium Phosphide, Aluminum Hydride, Sodium Borohydride, Boron Lithium Aluminum Alloy

III. Oxtdzers
A. Nitrates:
B. Chlorates:
c. Perchlorates:
Potassium Nirrate, Calcium Nitrate, Sodium Nitrate, Zinc Nitrate, Thallium Nitrate
D. Oxides:
Potassium Chlorate, Lithium Chlorate, Calcium Chlorate, Strontium Chlorate
Lithium Perchlorate, Magnesium Perchlorato
E. Oxidizing Acids:
Manganese Diaxide, Magnesium Dioxide, Chromium Trioxide, Lead Oxide (Brown)
Nitric Acid (greater than 40\%), Perchioric Acid, Periodic Acid 


\section{Appendix B \\ Chemical Compatibility Guide}

continued...

IV, Conrosives

A. Acids

1. Mineral Acids:

Hydrochloric Acid, Sulfuric Acid, Nitric Acid (Less than 40\%)。 Phosphoric Acid

2. Organic Acids:

Acetic Acid, Acetic Anhydride, Acetyl Bromide, Formic Acid, Isöpentanoic Acid

3. Reactive Corrosives:

Phosphorus Trichloride, Phosphorus Pentachloride, Antimany Trichloride, Phosphoric Anhydride

B. Bases

1. Inorganics:

Sodium hydroxide, Potassium Hydroxide, Ammonium Hydroxid̀, Sodium Hypochlorite

2. Organics:

Amino Propyl Diethanolamine, Amino Ethyl Piperazine, Acetyl lodide, Benzoyl Chloride, Dimethyl Sulfonyl Chioride

3. Hydrazine Solutions

v. Poisons
A. Organics:
B. Metallics:
Phenol, Acrylamide, Benzoin, Benzidine, Aniline
C. Inorganic Cyanides:
Potassium Cyanide, Sodium Cyanido, Cyanogon Bromide

VI. Potentlal Reacthea (Explosive)
A. Trinitros:
B. Azides:
Trinitrophenal (Picric Acid), Trinitrobenzene, Trinitrotoluene (TNT), Trinitromethane
C. Amides:
Hydrogen Azide, Ammonium Azide, Barium Azide, Chlorine Azide, Silver Azide
D. Monomeric Isocyanates:
Trinitroaniline (Picramide), Sodamide, Potassium Amide
Hydrocyanic Acid, Isothiocyanuric Acid

VII. Othar Ctremical Waste
A. Separate Organics from Inorganics*
B. Separate Liquids from Solids

VIII. Dobris

A. Separate Organics from Inorganics" and label packaging with all contaminants present.

-Inorganic materials contaminated with organic components should be segregated as organic. 
Appendix C: Who to Call for Further Information

Number

Item

Person

5251

5829

4644

7625

6146

7623

4644

7625

6146

7625

6242

4644

7625

6146

4838

4776

6015

6146

6146

6146

6146

5829

6146

5303

6146

7625

6146

7625

7615

EH\&S general number

Industrial Hygiene Department general number

Environmental Specialist

HWHF Technician

Rita Cummings

HWHF Manager

Reggie Martinez

Environmental Monitoring

Help in locating WAAs

Help in locating WAAs

Help in locating WAAs

Charlie Carr

Gary Schleimer

Rita Cummings

Absorbant for spill cleanup

Reggie Martinez

Charlie Carr

Reggie Martinez

Chemicals, solvents, surplus

Materiel Management

Compatibility, chemical

Rita Cummings

(what can be stored next to what and where)

Compatibility, chemical

Reggie Martinez

(what can be stored next to what and where)

Containers for hazardous waste (what type to use)

Charlie Carr

Fax number, hazardous waste disposal

Fax number, EH\&S

Grounding and bonding wires

WAA Daily Inspection Checklist

WAAs, establishing or deactivating

WAA site record-keeping requirements

WAA site guidelines for maintenance

Hazardous material, information prior to ordering

Hazardous waste not picked up in 3 days

Lead, scrap, not contaminated

Labeling "empty" hazardous waste containers

Labeling "empty" hazardous waste containers

Labeling hazardous waste containers

Labeling hazardous waste containers

Liquid destined for EBMUD sewer

Fire Department

Charlie Carr

Charlie Carr

Charlie Carr

Charlie Carr

Industrial Hygiene

Department

Charlie Carr

Salvage

Charlie Carr

Reggie Martinez

Charlie Carr

Reggie Martinez

Charles Smith 
Industrial Hygiene

4644 MDSDs, interpretation of

Department

7609

Mercury, spill

Rita Cummings

Glenn Garabedian

7625

Mercury, spill

5303

5303

Metal, precious, recycling of

Reggie Martinez

Metal, scrap, for recycling

Salvage

Salvage

Minimizing hazardous waste in your area

Rita Cummings

Mixing waste (what's safe to mix?)

Rita Cummings

PCBs, disposal of

PPE (Personal Protective Equipment)

Reggie Martinez

Industrial Hygiene

Radioisotope safety

7603

7621

4644

Radioisotope transportation

Regulations, hazardous waste, clarification of

4644 Regulations, hazardous waste, copies of

7625

Spill cleanup supplies

5251

5258

Training, to sign up for

Training, hazardous waste, course content

4644

Training, medical and biological waste, course content

6266 Chemical exposure (skin, hair, eyes, swallowed, inhalation)

7911 Chemical exposure (skin, hair, eyes, swallowed, inhalation)

Jim Haley

Dick Harvey

Rita Cummings

Rita Cummings

Reggie Martinez EH\&S front desk Jack Bartley

Rita Cummings

Medical Services (normal working hours)

Fire Department (off hours)

Hazardous Material Spills

1-800-523-2222

Poison Control Hotline for help with chemical exposures

1-415-476-6600 Poison Control Hotline for help with chemical exposures 
Appendix D

Forms 


\section{LAWRENCE BERKELEY LABORATORY WASTE ACCUMULATION AREA DAILY INSPECTION CHECKLIST}

Bldg./Location:

Inspector:
Time A.M.:

WEEK OF
Time P.M.

THRU

\section{MORNING CHECKLIST}

1. Check all drum tops for standing water

2. Check all pallets for standing water

3. Check all drums for closed/sealed lids

4. Check all drums for correct/readable labels

5. Are aisles and doorways free of obstructions?

6. Are berm areas and containment systems free of leaks and spills?

7. Are all start dates in compliance with the 60-day limitation?

\section{EVENING CHECKLIST}

1. Check that all drum covers are on tight

2. Check that all drums are labeled

3. Check that all areas are secured and gates are locked

4.

5.

\begin{tabular}{|c|c|c|}
\hline $\begin{array}{c}\text { Date } \\
\text { Conrected }\end{array}$ & $\begin{array}{c}\text { Comecled } \\
\text { By }\end{array}$ & \\
\hline & & \\
\hline & & \\
\hline & & \\
\hline & & \\
\hline & & \\
\hline & & \\
\hline & & \\
\hline
\end{tabular}




\section{LAWRENCE BERKELEY LABORATORY RECORD OF WASTE ACCUMULATION}

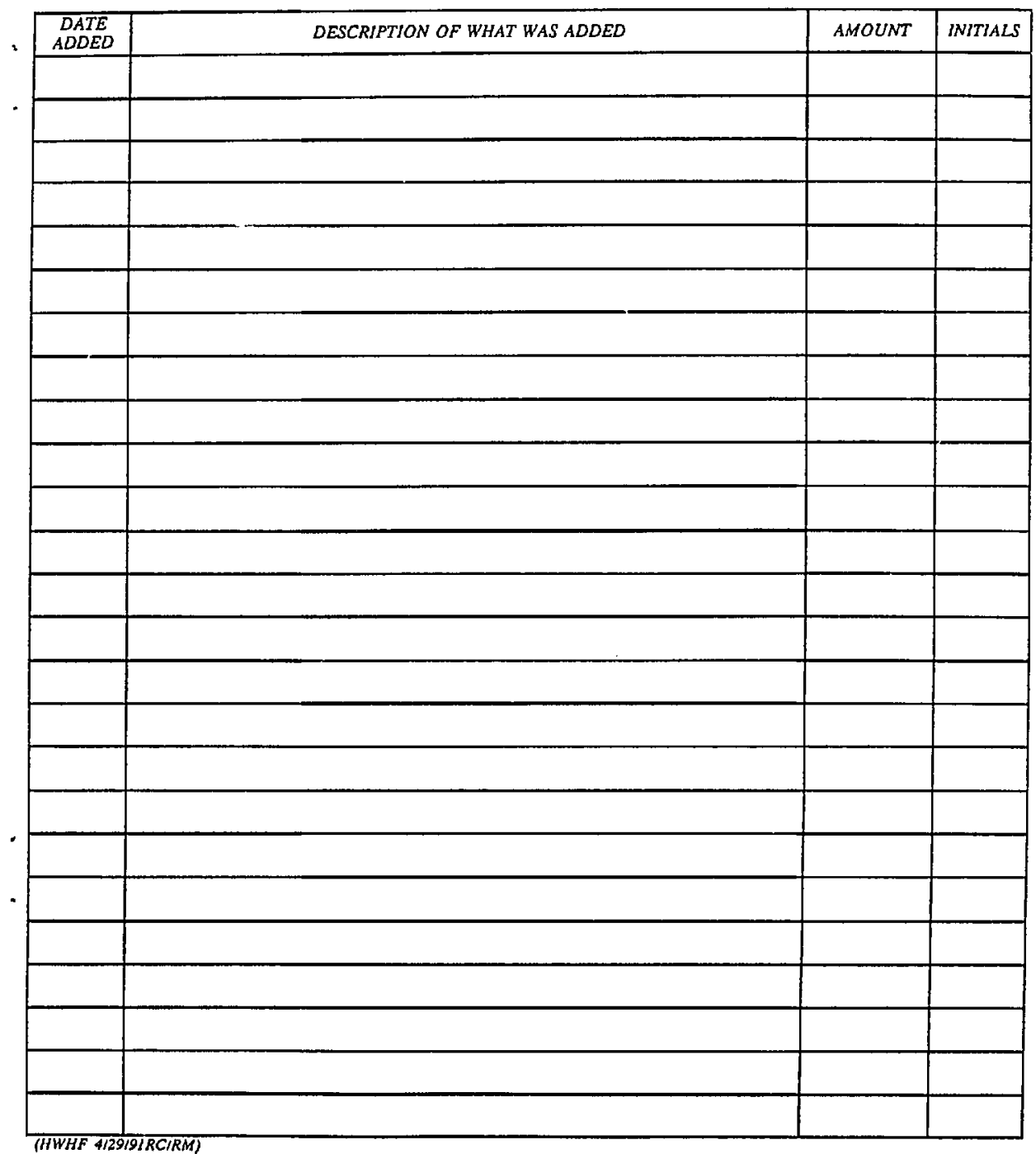

